\title{
Impacto de uma universidade na comunidade local por meio de projetos de extensão: o caso de uma unidade acadêmica de tecnologia
}

\author{
Camila Alves Damásio ${ }^{1}$ \\ Wagner Ragi Curi Filho ${ }^{2}$
}

\begin{abstract}
RESUMO
Este trabalho analisou o impacto de uma universidade a partir da atuação da extensão em uma unidade acadêmica das áreas tecnológicas de uma universidade pública brasileira. A extensão universitária pode ser considerada como um dos outputs de uma universidade como destacado em Cox e Taylor (2006) e Curi Filho (2018). Os dados foram coletados a partir de pesquisa documental, realizada na página da universidade, dedicada a divulgar os projetos da instituição. Foram identificados e analisados 39 projetos de extensão, desenvolvidos entre 2015 e 2019. Tendo como base as diretrizes da extensão universitária, os projetos foram analisados a partir das seguintes características: áreas de atuação; público-alvo; se eles eram voltados para o desenvolvimento de tecnologias sociais; e como se deram as formas de participação da comunidade em cada projeto. Diante do exposto nos resumos foi possível notar: que a maioria dos projetos são área de educação; que há projetos que desenvolvem tecnologias sociais embora não sejam a maioria; que há uma dificuldade de compreender a dialogicidade e de avaliar a transformação social; e que os projetos prezam pela interdisciplinaridade e interprofissionalidade.
\end{abstract}

Palavras-chave: Impacto da Universidade. Projetos de Extensão. Diretrizes da Extensão Universitária.

\footnotetext{
${ }^{1}$ Graduanda em Engenharia de Produção pela Universidade Federal de Ouro Preto - UFOP, Campus de João Monlevade, MG, Brasil. E-mail: camila.damasio@aluno.ufop.edu.br.

${ }^{2}$ Graduado e Mestre em Engenharia de Produção, ambos pela Universidade Federal de Minas Gerais - UFMG. Doutor em Administração de Empresas pela Fundação Getulio Vargas - FGV, SP. É professor, pesquisador e coordenador do curso de Engenharia de Produção da Universidade Federal de Ouro Preto - UFOP, Campus de João Monlevade, MG, Brasil. E-mail: wagner@ufop.edu.br.
} 


\title{
Impact of a university in the local community through extension projects: the case of a technology center higher education
}

\begin{abstract}
This work analyzed impact of a university by means of the performance of the extensions projects in a technology higher education center a Brazilian public university. University extension can be considered as one of the outputs of a university as highlighted in Cox and Taylor (2006) and Curi Filho (2018). The data were collected from a documentary research carried out on the university page. It identified and analyzed 39 extension projects that were development between 2015 and 2019 from unit academic researched. Based on university extension guidelines and goal this work, it analyzed the projects considering the following characteristics: areas of activity; target audience; if there was any project focus in social technologies; and how the community participated in the projects. In view of what was exposed in the abstracts analyzed, it was possible to note: that most projects are in the area of education; that there are projects that develop social technologies although they do not constitute the majority; that there is a difficulty in understanding dialogicity and assessing social transformation; and what projects they value for interdisciplinarity and interprofessionality.
\end{abstract}

Keywords: Impact of a University. Extension Projects. University Extension Guidelines.

Artigo recebido em: 30/04/2020

Aceito em: 02/06/2020 


\section{INTRODUÇÃ̃O}

Segundo Bachmann (2018), a universidade, por meio da extensão universitária, tem a finalidade do compartilhamento do conhecimento e mobilização comunitária, de forma que o conhecimento teórico adquirido na universidade, juntamente com a possibilidade da vivência prática, seja capaz de gerar transformações, em resposta às demandas da sociedade (CARBONARI; PEREIRA, 2007). Em uma perspectiva Freiriana, a extensão universitária também permitirá troca de saberes de uma maneira que a comunidade aprenda com os saberes populares e vice-versa (FREIRE, 2010).

Portanto, pode-se considerar que a extensão passa a ser uma estratégia de buscar ou justificar maiores investimentos e, ao mesmo tempo, promover uma legitimação do saber acadêmico na direção das demandas sociais, tornando-o mais aplicado e buscando sua validação em situações mais tangíveis (COELHO, 2014) no sentido de uma universidade mais contributiva com a sociedade como um todo, e não apenas um sistema produtivo capitalista (CHAUÍ, 2001; VIANA et al., 2015; FERREIRA, 2016).

Diante das possibilidades de extensão e da crescente preocupação em avaliar o impacto que uma universidade traz para a comunidade onde está instalada, crescem os estudos que abordam a relação da universidade com a comunidade local (ROLIM; SERRA, 2009; MUSSELIN, 2013; KANTOR; WHALLEY, 2014). Nesse sentido, dentre as possíveis formas de impacto de instituição universitária na comunidade, estão os projetos de extensão (CURI FILHO, 2018; SÁ, 2019). Faz-se, portanto, o questionamento: Como se dá o impacto da extensão universitária na comunidade do entorno da universidade? Visando contribuir com a resposta para essa pergunta, este trabalho apresenta como objetivo geral uma avaliação das características dos projetos de extensão de uma unidade acadêmica de uma universidade pública brasileira.

A partir de uma análise documental, analisou-se os resumos dos projetos de extensão realizados pela unidade acadêmica, situada no interior de Minas Gerais e que possui apenas cursos de graduação nas áreas tecnológicas.

Em suma, tem-se que o objetivo geral desse trabalho pode ser desmembrado nos seguintes objetivos específicos: identificar os projetos de extensão que desenvolvem tecnologias sociais; identificar o público-alvo e áreas de cada projeto de extensão; classificar as formas de participação da comunidade nos projetos de extensão e avaliar os projetos de extensão em face das diretrizes da extensão universitária. 
Cabe ressaltar que, embora se reconheça a realidade dialógica da extensão, o intuito desse trabalho é compreender a extensão a partir das características idiossincráticas de cada projeto de extensão avaliado, e não a partir de estudos in loco em comunidades ou ainda de uma potencial análise crítica que se possa elaborar da atuação da extensão universitária nas instituições de ensino superior brasileiras.

\section{METODOLOGIA}

Os caminhos metodológicos percorridos foram retratados em dois subtópicos: o primeiro subtópico caracteriza a pesquisa e especifica as técnicas de coleta de dados, e o segundo detalha a técnica de análise de dados aplicada na pesquisa.

\subsection{Caracterização da pesquisa e as técnicas de coleta de dados}

Esta pesquisa é classificada como um estudo descritivo de abordagem mista, qualiquantitativa (CRESWELL, 2007). A pesquisa é qualitativa pois se realizou uma leitura acurada dos resumos dos projetos de extensão, a fim de compreendê-los. O caráter quantitativo se configura no fato de que foi possível quantificar numericamente características dos projetos de extensão analisados.

A unidade analisada neste trabalho possui cerca de 1.300 alunos de graduação de 4 cursos, todos da área de tecnologias. Há ainda um curso de mestrado, também na área de tecnologia. Ressalta-se ainda que a unidade selecionada é única na cidade, mas faz parte de uma universidade com 12 unidades, das quais 11 delas estão na cidade sede.

Para a realização dessa pesquisa utilizou-se como forma de coleta de dados a pesquisa documental. De acordo com Helder (2006, p. 1-2), "A técnica documental vale-se de documentos originais, que ainda não receberam tratamento analítico por nenhum autor. [...] é uma das técnicas decisivas para a pesquisa em ciências sociais e humanas". Assim, todo o trabalho foi realizado a partir de dados encontrados numa página da universidade, dedicada a divulgar um evento anual que tem como objetivo apresentar os projetos da universidade, dentre os quais se destacam projetos de Pesquisa e Extensão.

A coleta de dados foi realizada em março de 2020. Pesquisou-se os resumos de todos os projetos de extensão da unidade acadêmica selecionada, tomando como referência os projetos apresentados entre os anos de 2015 e 2019. Isso resultou em um retorno de 57 
resumos/projetos de extensão. No entanto, notou-se que alguns foram contabilizados mais de uma vez, pois tiveram duração por mais de um ano. Assim, desconsiderou-se as duplicidades e restaram 39 resumos/projetos, os quais foram analisados.

\subsection{Análise de dados}

Os dados obtidos da pesquisa documental foram tabulados em uma planilha compreendendo as seguintes colunas: título, área da extensão, público-alvo do projeto, coordenador do projeto, departamento de origem do coordenador do projeto, referência ao desenvolvimento de tecnologias sociais além das diretrizes da extensão (FORPROEX, 2012).

A própria identificação do resumo apresentava, além do título, a área do projeto e seu coordenador. As áreas temáticas foram definidas de acordo com a Política Nacional de Extensão Universitária (FORPROEX, 2012), a saber: Comunicação, Cultura, Direitos Humanos e Justiça, Educação, Meio Ambiente, Saúde, Tecnologia e Produção, e Trabalho. A partir do nome do coordenador foi possível identificar seu departamento.

Após sistematizar as informações iniciais (título, área do projeto, coordenador do projeto e departamento de origem do coordenador), uma análise qualitativa dos resumos permitiu identificar quais eram os públicos-alvo e como as diretrizes da extensão universitária eram abordadas em cada projeto. Assim, verificou-se como cada projeto trabalhava as seguintes temáticas: interação dialógica; interdisciplinariedade e interprofissionalidade; indissociabilidade entre ensino, pesquisa e extensão; impacto na formação do estudante; e o impacto e transformação social.

Para análise da interação dialógica, verificou-se o grau de interação de cada projeto com a comunidade. Assim, os projetos foram analisados e classificados conforme as formas de participação da comunidade nos projetos extensão, tal como a participação ativa, participação passiva e participação parcialmente passiva.

A participação ativa ocorre quando o projeto permite uma “[...] organização dinâmica de um grupo ou comunidade que assume o compromisso da luta e da conquista por meio do comprometimento direto nos assuntos de seu interesse" (SAYAGO, 2008, p. 546).

A participação passiva pode ser definida como semiparticipação ou uma mera representação. Tem um sentido mais quantitativo. É geralmente uma participação mais esporádica. “[...] Um exemplo de participação passiva é a consulta ou informação que, 
solicitada ou oferecida, fornece o indivíduo ou grupo. O censo talvez seja uma clara expressão disso" (SAYAGO, 2008, p. 546).

Já a participação parcialmente passiva ocorre quando o processo em questão chega ao conhecimento de muitas pessoas, mas poucas têm poder para decidir algo de fato, o indivíduo tem comportamento desejado, sem interferir no processo (SIMOES; SIMOES, 2015).

Ainda sob uma perspectiva qualitativa, analisou-se também se os projetos fazem referência ao desenvolvimento de tecnologia social, avaliando especialmente, aqueles projetos direcionados a organizações produtivas como associações e cooperativas.

Após a identificação e sistematização das características de cada projeto, analisadas em uma perspectiva qualitativa, foi possível realizar agrupamentos dos projetos considerando suas similaridades, possibilitando assim uma quantificação do perfil dos projetos analisados.

\section{REVISÃO BIBLIOGRÁFICA}

\subsection{Os impactos de uma universidade}

Acredita-se que a presença de uma universidade gera impactos diversificados nas comunidades locais em que estão inseridas. Tem-se por exemplo, a possibilidade de crescimento econômico (ex. TAROCCO et al., 2014), desenvolvimento de tecnologias (ex. KANTOR; WHALLEY, 2014; SCANDURA, 2016) e impacto a partir dos resultados de projetos de pesquisa e extensão voltados para públicos-alvo específicos.

Segundo Fava-de-Moraes (2000), Isaac et al. (2012) e Hoff et al. (2017) o papel da universidade é fundamental no desenvolvimento socioeconômico de uma região, especialmente, quando fundamentado em uma política científica-tecnológica articulada no espaço das relações entre universidade, Estado, setor produtivo e outros setores sociais (LEYDESDORFF; MEYER, 2003; JOHNSON, 2008; IPIRANGA; FREITAS; PAIVA, 2010; DOIN; ROSA, 2019).

A despeito do impacto positivo da universidade no desenvolvimento regional, são muitos os aspectos que devem ser avaliados para compreender tal impacto, em sua maioria de natureza complexa. Destacam a necessidade de se avaliar: a integração de projetos de pesquisa/extensão e a comunidade local; a criação de novas empresas de serviços ou 
tecnologias avançadas a partir de projetos de pesquisa e/ou extensão da universidade; e participação em organizações eficazes econômica e socialmente. Em qualquer dos casos, o objetivo é contribuir para mudanças tecnológicas, econômicas e sociais que afetem positivamente o desenvolvimento local, organizações e das pessoas individual e coletivamente (FAVA-DE-MORAES, 2000, WYK; SAAYMAN; RSSOUW; 2013; SCANDURA, 2016).

Comumente, quando se pensa na palavra impacto, vem à tona o que pode ser considerado como impacto socioeconômico. Todavia, segundo Curi Filho (2018), sob a perspectiva dos tipos de impactos, as universidades proporcionam impactos que podem ser agrupados em 3 tipos. Além do impacto socioeconômico, há o impacto científicotecnológico e o impacto na cultura e na imagem da região tornando o processo de compreensão da relação entre universidade e comunidade ainda mais complexo.

Ante as dificuldades para se medir o impacto de uma universidade, autores como Cox e Taylor (2006), Kureski e Rolim (2009), e Lendel (2015) propõem que se pense uma avaliação que considere a ideia de inputs e outputs. Os inputs são demandas buscadas pela universidade na sociedade tal como políticas públicas. Já os outputs constituem-se como sendo os produtos e serviços gerados pela universidade.

Segundo Curi Filho (2018), há outputs que, simultaneamente, podem gerar impacto dos 3 tipos. Assim, por exemplo, um mesmo projeto de extensão pode gerar: impacto socioeconômico na medida em que contribui para melhoria social e/ou econômico de algum grupo de pessoas; pode gerar impacto científico-tecnológico na medida em que desenvolve uma tecnologia social; e impacto na cultura e imagem da região na medida em que pode disseminar a cidade ou região a partir de aparições na imprensa.

Para sistematizar a ideia de inputs e outputs e identificar onde os projetos de extensão estão nesse modelo, pode-se avaliar a Figura 1. Nela são apresentadas uma proposta de inputs e outputs a serem analisados em um processo de avaliação do impacto socioeconômico de uma universidade. Associado à cada input e output, também é apresentado um conjunto de indicadores que pode ser tomado como base para a avaliação do impacto da universidade na comunidade local. A seta na Figura 1 destaca o output projetos de extensão como sendo um dos outputs da universidade.

Ademais, ressalta-se, que além de se considerar os projetos de extensão como outputs de uma avaliação do impacto socioeconômicos, estes poderiam também serem compreendidos como outputs de um potencial impacto científico-tecnológico da 
universidade na comunidade local como por exemplo, quando projetos de extensão, desenvolvem tecnologias sociais.

Figura 1: Outputs e inputs: impacto socioeconômico de uma universidade

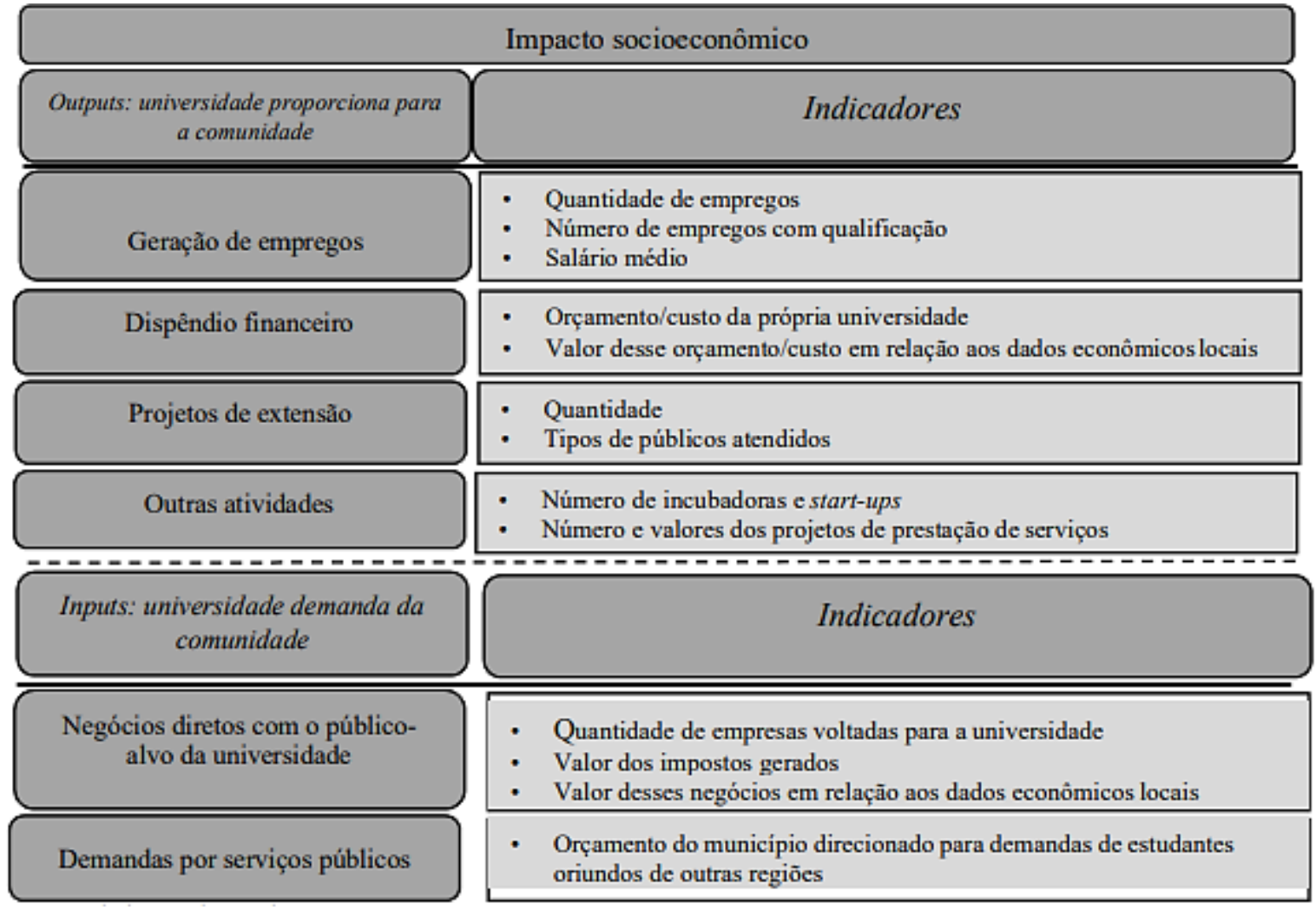

Fonte: Adaptada de Curi Filho (2018).

Embora seja possível problematizar as diferentes maneiras que uma universidade impacta na comunidade local, por exemplo, analisando aspectos sociológicos de cada ação de extensão ou de pesquisa ou de outra natureza, este trabalho segue a proposta da Figura 1 e limita-se a analisar os projetos de extensão considerando sua quantidade, públicos-alvo e suas características.

Ainda é necessário frisar, que ao se pensar em público-alvo de um projeto de extensão, se considera que, de maneira geral, cada projeto de extensão possui um impacto em uma pequena parcela da população, esta parcela pode ser maior ou menor e depende da natureza e alcance do projeto. 


\subsection{Extensão universitária}

No geral, um projeto de universidade envolve necessariamente a escolha de objetivos e metas que assinalam o tipo de sociedade, homem e mundo que se deseja construir. A inserção da extensão universitária nos cursos de graduação (conforme previsto na Portaria 1.350 do MEC do ano de 2018) aponta a possibilidade de reestruturação curricular que mobiliza a integração dos sujeitos em um processo de partilha solidária de saberes, fazeres e sonhos, na luta pela democratização da educação e pela transformação da realidade educativa historicamente elitizada e excludente na educação superior (ANDRADE; MAROSINI; LOPES, 2019).

A universidade, ao fomentar atividades extensionistas, permite aos estudantes aumentar a sua participação social e desenvolver cidadania e de certo modo possibilitar a sua qualificação enquanto profissional. A interação com a sociedade que, detentora de conhecimentos e de desenvolvimento de habilidades, propiciará ao estudante uma maior segurança para o exercício profissional cidadã após a formação acadêmica (COELHO, 2014).

A extensão universitária, segundo De Paula (2013), deve contribuir especialmente para a interligação entre a cultura científica e a cultura das humanidades. As ações de extensão devem buscar contribuir para o desenvolvimento social, de modo que a universidade favoreça para os processos de inovação social (CUNHA; BENNEWORT, 2013). Outrossim, a extensão universitária vem sendo considerada como um ambiente privilegiado para a produção do conhecimento de forma coletiva e em interação com o mundo real, se constituindo em um dos caminhos mais promissores para a construção de uma universidade mais aberta, ética, solidária e participativa, em favor de uma educação mais pluralista, transgressora e emancipatória, possibilitando as gerações futuras o direito de repensar o mundo de forma mais colaborativa e sustentável (DAVID et al., 2014).

De acordo com o Forproex (2012), para que se possa acontecer uma extensão, há de se respeitar algumas diretrizes conhecidas como Diretrizes da Extensão Universitária. A primeira é a interação dialógica, que orienta o desenvolvimento de relações entre universidade e setores sociais marcadas pelo diálogo e troca de saberes, superando-se, assim, o discurso da hegemonia acadêmica e substituindo-o pela ideia de aliança com movimentos, setores e organizações sociais (FREIRE, 2010).

A segunda refere-se à interdisciplinaridade e à interprofissionalidade que busca superar a dicotomia generalização/especialização, combinando especialização e 
consideração da complexidade inerente às comunidades, setores e grupos sociais, com os quais se desenvolvem as ações de extensão, ou aos próprios objetivos e objetos dessas ações (TAVARES, 2008).

A terceira é a indissociabilidade entre ensino, pesquisa e extensão em que na relação entre extensão e pesquisa, abrem-se múltiplas possibilidades de articulação entre a universidade e a sociedade. Visando à produção de conhecimento, a extensão universitária sustenta-se principalmente em metodologias participativas, no formato investigação-ação (ou pesquisa-ação), que priorizam métodos de análise inovadores, a participação dos atores sociais e o diálogo (PUHL; DRESCH, 2016).

A quarta diretriz refere-se ao impacto na formação do estudante em que as atividades de extensão universitária constituem aportes decisivos à formação do estudante (NAVES, 2015; GOMES; SILVA, 2019), seja pela ampliação do universo de referência que ensejam, seja pelo contato direto com as grandes questões contemporâneas que possibilitam.

Por fim, a última diretriz a ser considerada é o impacto e a transformação social que reafirma a extensão universitária como o mecanismo por meio do qual se estabelece a interrelação da universidade com os outros setores da sociedade, com vistas a uma atuação transformadora, voltada para os interesses e as necessidades da maioria da população e propiciadora do desenvolvimento social e regional, assim como para o aprimoramento das políticas públicas (FREIRE, 2010; OLIVEIRA, 2013).

\subsection{Tecnologia social}

Tendo em vista que este trabalho possui o objetivo de avaliar o impacto de uma unidade acadêmica que possui cursos e docentes apenas das áreas das tecnologias, entendese necessário avaliar os projetos de extensão no que diz respeito ao desenvolvimento de tecnologia social.

David et al. (2014), afirmam que a tecnologia social está cada vez mais se expandindo e constituindo redes sociais, capazes de disponibilizar experiências construídas e atendendo as necessidades próprias da comunidade e com possibilidades de se adaptarem a outras comunidades, tecnologias que tem aplicabilidade na saúde, educação, habitação, desenvolvimento de tecnologias, geração de renda e outros.

Segundo Dagnino (2010), a tecnologia social, é definida como produtos, técnicas e/ou metodologias reaplicáveis, desenvolvidas na interação com a comunidade e que representem 
efetivas soluções de transformação social, sendo esta, segundo o próprio autor, a definição mais frequente usada no Brasil. Desse modo, a tecnologia social configura-se como uma alternativa frente à tecnologia convencional, abrindo caminhos e estendendo pontes entre as demandas da sociedade e suas soluções e no alcance de um modelo de desenvolvimento social que tenha centralidade no processo de inclusão social e, como atores principais, a própria sociedade (FERNANDES; MACIEL, 2010).

De Almeida (2010), afirma que a concepção da tecnologia social vai além do enfoque no artefato e se insere no contexto e na realidade concreta dos sujeitos para transformar, configurando-se como instrumento pedagógico e político. Pedagógico na medida em que é um processo de aprendizagem e, político na medida em que situa-se no mundo das pessoas e de seu espaço, sua organização, de forma independente, autônoma e autogestionária.

As ações da universidade pública, pela via da Tecnologia Social, criadas a partir da relação ciência, tecnologia e sociedade, fortalecem o vínculo desta com o seu contexto social (CALDAS et al., 2007). Todo conhecimento surge na própria sociedade e deve estar comprometido com esta. Presume-se um desenvolvimento científico tecnológico responsável com a sustentabilidade da sociedade, sendo essa a finalidade principal do conhecimento produzido (KLOSSOWSKI; FREITAS; FREITAS, 2016).

Por fim, é de fundamental relevância associar as práticas de tecnologia social às atividades de pesquisa e extensão universitária objetivando o estabelecimento do processo de legitimação, constituindo esse espaço em um ambiente estratégico para a inovação e intervenção social. (OLIVEIRA, 2013).

\section{RESULTADOS}

Dos 39 projetos identificados, 15 projetos foram voltados para a educação; 7 foram classificados nas áreas de tecnologia e produção; 4 voltados para o meio ambiente; 5 resumos/projetos voltados para o trabalho; 4 voltados para a saúde; 2 voltados para a cultura e 2 resumos de projetos com características voltadas para os direitos humanos. O Quadro 1 apresenta os projetos agrupados por área e públicos-alvo. 
Quadro 1: Projetos segundo áreas de atuação e respectivos públicos-alvo

\begin{tabular}{|c|c|l|}
\hline Área & $\begin{array}{c}\mathbf{N}^{\mathbf{0}} \text {. de } \\
\text { Projetos }\end{array}$ & \multicolumn{1}{|c|}{ Públicos-alvo } \\
\hline Educação & 15 & $\begin{array}{l}\text { Alunos e docentes do ensino fundamental e médio de escolas públicas } \\
\text { da cidade; comunidade local; alunos surdos do Ensino Fundamental I } \\
\text { e II. }\end{array}$ \\
\hline $\begin{array}{c}\text { Tecnologia e } \\
\text { Produção }\end{array}$ & 7 & $\begin{array}{l}\text { Comunidade local; alunos de escolas públicas; gestores do Hospital } \\
\text { da cidade; associações comunitárias e feirantes; um asilo. }\end{array}$ \\
\hline Trabalho & 5 & $\begin{array}{l}\text { Cooperadas de costureiras; comerciantes e industriais da cidade; } \\
\text { alunos do Ensino Médio e do Ensino Superior; consumidores da Feira } \\
\text { Livre da cidade; associados de um empreendimento solidário. }\end{array}$ \\
\hline $\begin{array}{c}\text { Meio } \\
\text { Ambiente }\end{array}$ & 4 & $\begin{array}{l}\text { Associação de catadores de materiais recicláveis; crianças de 8 a 10 } \\
\text { anos; alunos do ensino médio. }\end{array}$ \\
\hline Saúde & 4 & $\begin{array}{l}\text { Membros das Associações; pacientes e gestores do Hospital da } \\
\text { cidade; idosos da comunidade local. }\end{array}$ \\
\hline Cultura & 2 & $\begin{array}{l}\text { Associados e cooperados de associações e empreendimentos } \\
\text { autogestionários; comunidade local interessados por danca. }\end{array}$ \\
\hline $\begin{array}{c}\text { Direitos } \\
\text { Humanos }\end{array}$ & 2 & $\begin{array}{l}\text { Estudantes do ensino fundamental e médio; associados de um } \\
\text { empreendimento solidário. }\end{array}$ \\
\hline
\end{tabular}

Fonte: Autoria própria.

Ao analisar os públicos-alvo e áreas de atuação dos projetos observa-se que as escolas de ensino fundamental e médio, especialmente os discentes, dessas instituições são os principais públicos-alvo. Portanto, pode-se considerar que a existência da universidade impacta de alguma maneira (ao menos qualitativamente), esse público.

Após uma descrição inicial dos projetos em relação às áreas de atuação (conforme as áreas da extensão) e respectivos públicos-alvos, os projetos de extensão analisados foram agrupados no Quadro 2, que apresenta os projetos conforme áreas de atuação dos docentes coordenadores dos projetos.

Assim, as áreas de conhecimento foram divididas em 4, de maneira análoga aos departamentos acadêmicos existentes na unidade analisada. Portanto, os projetos foram classificados como: projetos de Física, Química e Matemática; projetos de Engenharia de Produção; projetos de Engenharia Elétrica e projetos de Computação e Sistemas. 
Quadro 2: Projetos segundo áreas de conhecimentos dos docentes

\begin{tabular}{|c|c|}
\hline Área & Nome dos Projetos (Adaptados) \\
\hline \multirow{10}{*}{$\begin{array}{c}\text { Física, } \\
\text { Química e } \\
\text { Matemática }\end{array}$} & História da Ciência em Quadrinhos - volume 1 - Astronomia e Mecânica Clássica \\
\hline & Histórias em quadrinho em sites para divulgação científica da Física e da Matemática \\
\hline & Aprendendo Matemática através de atividades lúdicas \\
\hline & Desenvolvendo a Cidadania por meio de Reforço Escolar na área da química \\
\hline & Instrumentação para o ensino de Química utilizando materiais de baixo custo \\
\hline & Instrumentação para o ensino de Química a alunos com deficiência auditiva \\
\hline & Aplicação do ensino de Física através de um novo olhar para problemas ambientais \\
\hline & Novas perspectivas na aplicação da Física com olhar para problemas ambientais \\
\hline & Projeto Universidade Aberta para a Terceira Idade \\
\hline & Cursos de Inglês \\
\hline \multirow{15}{*}{$\begin{array}{c}\text { Engenharia de } \\
\text { Produção }\end{array}$} & Assessoria à associação de catadores de materiais recicláveis \\
\hline & Conscientização socioambiental por meio da gestão de resíduos \\
\hline & Consultoria acadêmica no comércio e industrias da região da cidade \\
\hline & $\begin{array}{l}\text { Inserção e disseminação das novas formas de Economia do ensino fundamental e médio } \\
\text { da cidade }\end{array}$ \\
\hline & Assistência sociotécnica à uma associação de produtores de farinha \\
\hline & Assessoria sociotécnica em uma cooperativa de costura \\
\hline & Projeto Dança do ventre \\
\hline & Economia Criativa \\
\hline & Economia Solidária e Saúde Mental: Uma 'Loucura' pela vida e cidadania \\
\hline & Gestão do conhecimento no Hospital da cidade \\
\hline & Ampliação e fortalecimento das atividades de uma associação \\
\hline & Gestão da informação no ciclo de vida das entidades \\
\hline & Pedagogia Empreendedora e Economia Solidária \\
\hline & Diagnóstico estrutural e socioeconômico da Feira Livre da cidade \\
\hline & Melhoria do fluxo de pacientes e processos do pronto socorro sob a ótica do lean health \\
\hline \multirow{6}{*}{$\begin{array}{l}\text { Engenharia } \\
\text { Elétrica }\end{array}$} & Auxílio ao Hospital da cidade para reduzir gastos com Energia Elétrica \\
\hline & Desenvolvimento de um sistema de chamadas à Enfermaria em um asilo da cidade \\
\hline & $\begin{array}{l}\text { Os caminhos do universo elétrico: uma contribuição para o fomento à qualificação } \\
\text { profissional dos estudantes do Ensino Médio da cidade }\end{array}$ \\
\hline & Capacitação empreendedora de jovens de ensino médio para atuação na área de elétrica \\
\hline & Uso consciente de energia elétrica e água potável nas residências de alunos de escolas \\
\hline & UNI-VER-CINEMA \\
\hline \multirow{8}{*}{$\begin{array}{l}\text { Engenharia de } \\
\text { Computação } \\
\text { de Sistemas }\end{array}$} & $\begin{array}{l}\text { Desenvolvimento de um Sistema Computacional de controle para o Cursinho } \\
\text { "Construindo o Futuro: Rumo à Universidade" }\end{array}$ \\
\hline & Jogando contra a dengue (X-Dengue VR) \\
\hline & Jogando contra a dengue (X-Dengue 2D) \\
\hline & Um jogo sério para apoiar o ensino de teoria musical \\
\hline & XDENGUE RA (REALIDADE AUMENTADA) \\
\hline & Jogando contra a dengue \\
\hline & Aprimoramento do Processo de Aprendizagem de Lógica de Programação \\
\hline & Portuga - Jogo Educativo para Auxiliar na Aprendizagem de Língua Portuguesa \\
\hline
\end{tabular}

Fonte: Autoria própria. 
Conforme pode ser verificado no Quadro 2, do total de 39 projetos analisados, 26\% foram desenvolvidos por professores das áreas de Física, Química e Matemática. Outros $38 \%$ foram desenvolvidos por professores da área de Engenharia de Produção. Na área da Engenharia Elétrica foram realizados $15 \%$ dos projetos. Por fim, os professores de Engenharia de Computação e Sistemas de Informação desenvolveram 21\% dos projetos. Salienta-se que, na unidade analisada, há número similar de professores de Engenharia de Produção e Engenharia Elétrica bem como de docentes de Física, Química e Matemática (somadas essas 3 áreas). Já os professores de Engenharia de Computação e Sistemas são em torno de $30 \%$ a mais que os outros 3 grupos.

\subsection{Identificando experiências de tecnologias sociais}

Ainda que os projetos analisados sejam de uma unidade acadêmica das áreas de engenharia, apenas $18 \%$ dos projetos, mostraram-se envolvidos com a temática da tecnologia social.

Tendo em vista a conceituação de tecnologia social, foi possível compreender que os projetos de assessorias, consultorias e gestão do conhecimento no hospital da cidade tinham como foco o desenvolvimento de produtos, técnicas e/ou metodologias desenvolvidas em ampla interação com a comunidade.

De forma análoga, também se identificou que os projetos voltados para a economia solidária e economia criativa, também podem se configurar como desenvolvedores de tecnologias na medida em que contribuem para o desenvolvimento de metodologias organizacionais com dialogicidade entre comunidade e academia.

\section{DISCUSSÃO}

Esta seção está organizada face às diretrizes da extensão universitária. Assim, cada uma das subseções se dedica a explicar os projetos analisados conforme os seguintes aspectos: interação dialógica; interdisciplinaridade e interprofissionalidade; indissociabilidade entre ensino, pesquisa e extensão; impacto na formação do estudante; e impacto e transformação social. 


\subsection{Interação dialógica}

Para compreender a interação dialógica avaliou-se os projetos a partir da participação da comunidade segundo as 3 formas supracitadas: participação ativa, participação passiva e participação parcialmente passiva.

Do total de 39 projetos, $36 \%$ foram considerados de participação ativa, ou sejam conseguiram debater e trabalhar uma extensão em sentido mais amplo, valorizando, de fato, a dialogicidade proposta por Paulo Freire (2010). Dentre esses projetos destacam-se: assessorias sociotécnicas realizadas em associações e cooperativas da cidade; projeto de gestão do conhecimento no hospital da cidade; projetos voltados para dança e cinema; e projeto de interação dos idosos da região com as instalações da universidade.

Os projetos com participação passiva totalizaram $28 \%$ dos projetos analisados. São projetos que oferecem algum produto ou serviço para a comunidade, porém a interação se torna esporádica ou até mesmo nula, pois a comunidade apenas recebe o que lhe é oferecido. Neste grupo também foram enquadrados cursos para a comunidade como o Pré-Vestibular Comunitário. Destacam ainda nesse grupo de projetos, a maioria dos projetos de Engenharia de Computação e Engenharia Elétrica, tais como aplicativo sobre Dengue e Conscientização do uso de energia.

Os projetos com participação parcialmente passiva da comunidade, compuseram $36 \%$ dos projetos avaliados. São projetos que trabalham em uma perspectiva de produção de produtos e serviços para a comunidade e em algum momento dessa produção, é necessário alguma interação, especialmente coleta de dados e informações. Alguns projetos desse grupo se destacam tais como projetos da Química, Física e Matemática, em que a grande parte está ligada ao ensino.

Salienta-se que, do ponto de vista da dialogicidade, projetos de extensão com participação passiva e parcialmente passiva não são interessantes, pois a ideia de interação dialógica que preside a noção contemporânea de extensão universitária não se restringe apenas a uma dimensão interindividual - entre sujeitos específicos.

\subsection{Interdisciplinaridade e interprofissionalidade}

Embora a unidade analisada possua apenas cursos da área de tecnologias, pode-se perceber que os projetos de extensão possuem caráter interdisciplinar e de 
interprofissionalidade. A começar pela análise de quantidade, a área que mais projetos possui é a de educação (15) e não a de tecnologia como poderia se esperar.

A unidade analisada possui docentes e técnicos-administrativos das áreas de Engenharia de Produção, Engenharia Elétrica, Engenharia de Computação e Sistemas além de Matemática, Física e Química. Todavia, os projetos transcendem essas áreas e profissões. Existem, por exemplo, projetos que envolvem Artes, Cultura e Economia Solidária.

Ademais, os projetos preveem desenvolvimento de competências comportamentais que vão além da formação básica das profissões base da unidade analisada, contribuindo para formação de um profissional atuante em diversas áreas, o que vai ao encontro a fala de Alves e Curi Filho (2017) que destacam a importância da interdisciplinaridade na solução de problemas sociais que possuem diversas faces e nuances.

\subsection{Indissociabilidade ensino-extensão-pesquisa}

Embora os projetos mencionem a integração da extensão com a pesquisa e o ensino, os resumos avaliados não apresentam evidências que haja integração entre extensão e pesquisa. Há sim uma preocupação com o ensino e utilização de conteúdos teóricos em contextos reais.

Avaliando o número de projetos e de docentes na unidade pesquisada percebe-se uma dificuldade da indissociabilidade entre ensino, pesquisa e extensão se consolidar, visto o pequeno número de professores e alunos envolvidos nos projetos de extensão. Foram 39 projetos de extensão em um período de 5 anos, sendo que há cerca de 80 professores efetivos na unidade analisada e 1.300 alunos de graduação.

Ressaltar-se também que, qualitativamente, os projetos não apresentam como a pesquisa se integrará à extensão, exceto pela ênfase que os resumos dão à necessidade dos discentes realizarem pesquisas teóricas antes de, efetivamente, realizar ações de extensão.

\subsection{Impacto na formação do estudante}

De acordo com os projetos de extensão desenvolvidos na instituição, tanto o processo teórico que se dá por meio da elaboração de atividades, quanto a prática vivenciada estimulam o acadêmico a ter maior criatividade, responsabilidade, organização, a busca pelo 
conhecimento e, principalmente, o desafio de vivenciar novas experiências. Assim, os projetos destacam a importância da extensão na formação dos estudantes bem como é destacado em Musselin et al. (2020) que afirma que a extensão favorece o desenvolvimento de novos conhecimentos para a formação dos estudantes, a partir da troca de experiência entre os sujeitos envolvidos.

Ao analisar os projetos percebe-se que sua concepção tem como preocupação essencial o desenvolvimento de competências, segundo as Diretrizes Curriculares Nacionais (DCNs), especialmente aquelas previstas paras as engenharias (MEC, 2019), nas quais se destacam, por exemplo, trabalhar de forma colaborativa e desenvolver sensibilidade.

\subsection{Impacto e transformação social}

Ao se avaliar os impactos na transformação social dos projetos de extensão da instituição em estudo observa-se uma carência de planejamento e formas de avaliação no impacto e transformação social. Também é de salientar a dificuldade dos projetos avaliados em inserir a comunidade nos processos avaliativos do êxito dos projetos.

Há projetos que tentam, ainda de forma incipiente, realizar pesquisas quantitativas tais como o projeto de aplicativo que mede o número de downloads do aplicativo ou projetos de educação que medem quantos alunos são atendidos. Não obstante, não é possível, por meio desses indicadores, avaliar transformação social tal como uma transformação da realidade conforme destacado em Dantas e De Souza (2019).

\section{CONCLUSÃO}

Este trabalho foi realizado com o intuito de analisar o impacto de uma universidade a partir da atuação da extensão. Para tal, analisou-se, inicialmente, 57 resumos de projetos de extensão de uma unidade acadêmica que possui apenas cursos das áreas tecnológicas. Esta unidade não encontra-se na cidade sede da universidade. Os resumos analisados correspondem aos projetos de extensão entre 2015 e 2019 e foram publicados em uma página da universidade dedicada a divulgar toda a produção de pesquisa e extensão da universidade. Os projetos que foram realizados por mais de um ano tiveram sua duplicidade considerada, assim, dos 57 resumos identificados inicialmente, analisou-se, de fato, 39 deles. 
A despeito das diversas possibilidades de se analisar como uma ação de extensão universitária impacta na comunidade, este trabalhou buscou, qualitativamente, compreender as características do projeto, não focado em realizar análise mais detalhadas em aspectos sociológicos ou antropológicos. Tampouco buscou-se avaliar o impacto quantitativo econômico. Buscou-se compreender características tais como áreas dos projetos, públicosalvo, como os projetos abordam as diretrizes da extensão universitária e se há presença de produção de tecnologias sociais.

Destaca-se como resultado que, embora a unidade estudada possua apenas cursos de tecnologias, os projetos analisados mostram que há atuação em todas as áreas da extensão definidas pelo Forproex (2012), a saber: comunicação; cultura; direitos humanos e justiça; educação; meio ambiente; saúde; tecnologia e produção; e trabalho. Salienta-se ainda que, diferentemente do que se possa imaginar, a maior quantidade (15, ou seja, 38\%) de projetos está na área de educação, e não de tecnologia.

Avaliando se os projetos eram voltados para o desenvolvimento de tecnologias sociais, observou-se que 7 deles (18\%) possuem essa característica. Já em relação à participação da comunidade tem-se que: a participação ativa totalizou 36\% dos projetos; a participação passiva compôs $28 \%$ dos projetos; e a participação parcialmente passiva contemplou $36 \%$ dos projetos. Pôde-se verificar com base nos resumos dos projetos, que a participação da comunidade ainda continua restrita e não se atentam a questão da dialogicidade como se debate na maioria dos trabalhos sobre a extensão universitária.

Além da dialogicidade, este trabalho avaliou os projetos de extensão em face das outras diretrizes da extensão universitária: interdisciplinaridade e interprofissionalidade; impacto na formação do estudante; indissociabilidade ensino-extensão-pesquisa; e impacto na transformação social. É de suma importância que a Pró-Reitoria de Extensão encontre meios de conscientizar os docentes sobre a Política Nacional de Extensão, para que desse modo, os professores extensionistas submetam propostas que estejam cada vez mais, embasadas nas cinco diretrizes do FORPROEX.

O fato de haver maior quantidade de projetos na área de educação, já sugere uma interdisciplinaridade que pôde ser comprovada na maioria dos projetos à medida em que se foi avaliando-os. Também foi de fácil identificação a preocupação dos projetos em impactar na formação dos estudantes. Todavia, quando se analisou os projetos visando compreender a indissociabilidade entre ensino, extensão e pesquisa e o impacto na transformação social, 
encontrou-se mais dificuldades que aquelas encontradas para avaliar a interdisciplinaridade e impacto na formação do estudante.

Não há clareza como a pesquisa está envolvida nos projetos e como o tripé ensinopesquisa-extensão se consolida. Também não há clareza de como os projetos avaliaram o impacto na transformação social, embora, qualitativamente, pode-se considerar que a maioria dos projetos conseguiram, de alguma maneira contribuir no desenvolvimento dos seus respectivos públicos-alvo.

Em suma, quando se pensa nos projetos de extensão como meio de impacto socioeconômico da universidade, pode-se chegar à conclusão que este impacto tende a ser positivo para aquelas pequenas parcelas da população que se constituem como públicos-alvo dos projetos. Talvez esse seja um aspecto importante de avaliação pois, visto que o impacto é pontual em pequenas parcelas da população, a universidade não consegue gerar um impacto de forma mais global na comunidade o que contribui para o questionamento que se tem, atualmente, acerca da atuação social das universidades, especialmente as universidades Públicas.

Ademais, este trabalho também sugere que a prática de projetos de extensão em uma unidade de tecnologias é incipiente (quando visto o número de projetos e professores) e também que a extensão nessa unidade carece de um debate maior de temas como a dialogicidade, a indissociabilidade ensino-extensão-pesquisa e a capacidade de avaliar e/ou realizar impacto e transformação social. É pertinente que se busque pela valorização da extensão, tais como as avaliações de desempenho dos professores, nas quais atividades de ensino, pesquisa e extensão deveriam possuir o mesmo valor, e a valorização da extensão nos encargos didáticos do professor.

Por fim, ressalta-se que essa pesquisa foi limitada quanto à forma de coleta dos dados, que se restringiu apenas à pesquisa documental, por meio de análise dos resumos dos projetos de extensão. Embora possibilite aprofundar a análise no contexto do objeto de estudo, não é apropriado generalizar os resultados obtidos utilizando deste método. Nesse sentido, para pesquisas futuras, pode-se, por exemplo, utilizar de entrevistas com docentes e discentes participantes de projetos de extensão, para se avaliar as suas percepções quanto aos projetos de extensão.

Sugere-se também buscar novas avaliações em unidades de tecnologias visando estabelecer comparações no sentido de identificar se os resultados deste trabalho cabem apenas à unidade analisada ou é similar a outros centros de tecnologias de educação superior. 
Outra limitação desse trabalho diz respeito ao fato da pesquisa não problematizar a extensão como um todo.

\section{REFERÊNCIAS}

ALVES, J. C. M.; CURI FILHO, W. R. Interdisciplinaridade, empoderamento e tecnologia social: experiências de economia solidária em uma ITCP. São Paulo: All Print Editora, 2017.

ANDRADE, R. M.; MOROSINI, M.; LOPES, D. A extensão universitária na perspectiva da universidade do encontro. Em Aberto, v. 32, n. 106, 2019.

BACHMANN, A. M. R. Extensão universitária e inovação social: estudo em uma universidade pública municipal. Revista Gestão \& Sustentabilidade Ambiental, v. 7, n. 1, p. 447-466, 2018.

CALDAS, ADS et al. Tecnologia social: cooperação universidade/comunidade para o desenvolvimento urbano regional e local sustentável. RDE-Revista de Desenvolvimento Econômico, v. 9, n. 16, 2007.

CARBONARI, M. E. Ehrhardt; PEREIRA, A. C. A extensão universitária no Brasil, do assistencialismo à sustentabilidade. Revista de Educação, v. 10, n. 10, 2007.

CHAUÍ, M. Escritos sobre a universidade. Unesp, 2001.

COELHO, G. C. O papel pedagógico da extensão universitária. Em Extensão, v. 13, n. 2, p. 11-24, 2014.

COX, S.; TAYLOR, J. The impact of a Business School on Regional Economic Development: a case study. Local Economy, v. 21, n. 2, 117-135, 2006.

CRESWELL, John W. Projeto de pesquisa: métodos qualitativos, quantitativos e mistos. 2. ed. Porto Alegre: Artmed, 2007.

CUNHA, J; BENNEWORTH, P. Universitie's contributions to social innovation: towards a theoretical framework. Netherlands, 2013.

CURI FILHO, W. R. Desenvolvimento de um modelo conceitual para avaliar o impacto de uma universidade em sua comunidade local. In: Anais do XLII Encontro Nacional de Administração. Curitiba, 2018.

DANTAS, D. C.; DE SOUSA, A. C. G. Avaliação dos Impactos na Transformação Social em um Projeto de Extensão Universitária. RAÍZES E RUMOS, v. 6, n. 2, p. 127-132, 2019 .

DAGNINO, R (Org.). Tecnologia social: ferramenta para construir outra sociedade. 2. ed. Campinas: Komedi, 2010. 
DAVID, ACC et al. Diálogo de experiências sobre extensão universitária e tecnologia social. RAÍZES E RUMOS, v. 2, n. 1, 2014.

DE ALMEIDA, A. S. A contribuição da extensão universitária para o desenvolvimento de Tecnologias Sociais. 2010.

DE PAULA, J. A. A extensão universitária: história, conceito e propostas. InterfacesRevista de Extensão da UFMG, v. 1, n. 1, p. 5-23, 2013.

DOIN, T.; ROSA, A. Interação Universidade-Empresa-Governo: o caso do Programa de Cooperação Educacional para Transferência de Conhecimento Brasil-Cingapura. Cadernos EBAPE, v. 17, nº 4, 940-958, 2019.

FAVA-DE-MORAES, F. Universidade, inovação e impacto socioeconômico. São Paulo em perspectiva, v. 14, n. 3, p. 8-11, 2000.

FERNANDES, R. M. C. e Maciel A. L. S. (Org.). Tecnologias sociais: experiências e contribuições para o desenvolvimento social e sustentável. Porto Alegre: Fundação Irmão José Otão, 2010.

FERREIRA, T. E.D. Os desafios de educar em valores na atualidade. Revista Engenharia de Interesse Social, v. 1, n⿳⺈⿴囗十 2016.

FREIRE, P. Extensão ou Comunicação. São Paulo: Paz e Terra, 2010.

FORPROEX - Fórum de Pró-Reitores de Extensão das Universidades Públicas Brasileiras. Política Nacional de Extensão Universitária. Manaus-AM, mai. 2012.

GOMES, F. S. C.; SILVA, A.S.V. A extensão universitária e a promoção de competências na formação do aluno de engenharia. In: Anais do XLVII Congresso Brasileiro de Educação em Engenharia, Fortaleza. 2019.

HELDER, R. Como fazer análise documental. Porto, Universidade de Algarve, 2006.

HOFF D.N.; PEREIRA, C.A.; DE PAULA, L. G. N. O impacto da universidade pública no desenvolvimento regional sob a luz da literatura internacional. Revista de Desenvolvimento Regional, v.22, $\mathrm{n}^{\mathrm{o}}, 1,510-527,2017$.

IPIRANGA, A.; FREITAS, A.; PAIVA, T. O empreendedorismo acadêmico no contexto da interação universidade - empresa - governo. Cadernos EBAPE, v. 8, $n^{\circ}$. 4, 676-693, 2010.

ISAAC, PH et al. Extensão Tecnológica-uma possibilidade viável com relevantes impactos socioeconômicos. 2012.

JOHNSON, W. H. A. Roles, resources, and benefits of intermediate organizations supporting triple helix collaborative $\mathbf{R} \&$ D: The case of Precarn. Techonvation, v. 28, n. 8, 495-505, 2008. 
KANTOR, S. e WHALLEY, A. Knowledge spillovers from research universities: evidence from endowment value shocks. Review of Economics and Statistics, v. 96, n.1, p. 171-188, 2014.

KLOSSOWSKI, A.; FREITAS, C. C. G.; FREITAS, F. P. M. O envolvimento da Universidade Pública em relação à Tecnologia Social (2001 a 2011). Revista Tecnologia e Sociedade, v. 12, n. 26, p. 61-80, 2016.

KURESKI, R.; ROLIM, C. Impacto econômico de curto prazo das Universidades Federais Brasileiras na economia brasileira. Revista Paranaense de Desenvolvimento, n.117, 29-51, 2009.

LENDEL, I. The Impact of Research Universities on Regional Economies: The Concept of University Products. Economic Development Quartely, v. 24, n. 3, 210-230, 2015.

LEYDESDORFF, L., \& MEYER, M. The Triple Helix of university-industrygovernment. Scientometrics, v. 58, n. 2, 191-20, .2003.

MEC. Portaria 1350 que institui diretrizes para as Políticas de Extensão da Educação Superior Brasileira. 2018.

MEC. Resolução No 2 de 24 Abril de 2019 que institui as Diretrizes Curriculares Nacionais do Curso de Graduação em Engenharia. 2019.

MUSSELIN, C. How peer review empowers the academic profession and university managers: Changes in relationships between the state, universities and the professoriate. Research Policy, v. 42,n.5, 2013, p. 1165-1173.

MUSSELIN, Lidiane et al. Ação extensionista de cuidado à saúde: a influência na formação profissional dos estudantes diplomados. Revista Diálogos, v. 23, n. 1, p. 7-19, 2020.

NAVES, E. T. Fazer-saber: reflexões sobre a função acadêmica da extensão universitária. Em Extensão, v. 14, nº 1, p. 9-29, 2015.

OLIVEIRA, Edson Marques. Tecnologia Social, Universidade e Sociedade: a Extensão como Espaço Estratégico de Intervenção. Revista Tecnologia e Sociedade, v. 9, n. 17, p. 5163, 2013.

PUHL, M.J. DRESH, O. I. O princípio da indissociabilidade entre ensino, pesquisa e extensão e o conhecimento. Revista Diálogos, v. 5, nº1, 37-55, 2016.

ROLIM, C. e SERRA, M. Instituições de Ensino Superior e Desenvolvimento Regional: O caso da Região Norte do Paraná. Revista de Economia, v.25, n. 3, p. 87-102, 2009.

SÁ, M. G. Em busca do impacto perdido? Experiências significativas com sentido local em pesquisa, ensino e extensão. FAROL-Revista de Estudos Organizacionais e Sociedade, v.6, nº15, 364-398, 2019.

SAYAGO, D. Participação: olhar para fora ou olhar para dentro. Ra Ximhai, v. 4, n. 3, p. 543-558, 2008. 
SCANDURA, A. University-industry collaboration and firms R\&D effort. Research Policy, v. 45, n.9, 2016, p. 1907-1922.

SIMOES, G. L.; SIMOES, J. M. Reflexões sobre o conceito de participação social no contexto brasileiro. Jornada Internacional de Políticas Públicas, v. 7, 2015.

TAVARES, D. E. A interdisciplinaridade na contemporaneidade - Qual o sentido? In: FAZENDA, I. O que é interdisciplinaridade? São Paulo: Cortez, 2008.

TAROCCO FILHO, J., SESSO FILHO, U.A., ESTEVES, E. Z.G. E KURESKI, R. Impacto econômico de curto prazo da Universidade Estadual de Londrina. Economia \& Região, v. 2, n.1, p.83-103, 2014.

VIANA, F. D. F.; SILVA, F.F.; ALVES, J. C. M.; CURI FILHO, W.R. El desarrollo económico y la extensión universitaria: uma Conversación entre Paulo Freire y Amartya Sem. In: Anais do XIII Congresso Latino Americano de Extensão Universitária. 2015.

WYK, L.V.; SAAYMAN, M.; ROSSOUW, R. Economic impact of the Klein Karoo National Arts Festival: investigating the application of different models. Journal of Economic and Financial Sciences, v. 6, n. 13, 129-152, 2013. 